\title{
Polyaniline as Additive to Improve the Anticorrosive Properties of Commercial Paint
}

\author{
ARRIETA ALVARO ${ }^{*}$, ISORA BARRERA ${ }^{2}$, JORGE MENDOZA $^{3}$ \\ ${ }^{1}$ Department of Biology and Chemistry, University of Sucre, Red Door neighborhood, Sincelejo, Colombia \\ ${ }^{2}$ Mercedes Abrego Educational Institution, Diag. 6-119, Tv. 1 \#6-1, Montería, Colombia \\ ${ }^{3}$ Department of Mechanical Engineering, University of Córdoba, Road 6 No. 76-103, Montería, Colombia
}

\begin{abstract}
Corrosion is one of the great problems that many industries face and that generates losses of millions of dollars worldwide. The aim of this work was to evaluate the capacity of polyaniline to increase the anticorrosive capacity of a commercial epoxy paint. Polyaniline was chemically synthesized by oxidation with ammonium persulfate and doped with oleic acid. Polyaniline was added to the paint in various concentrations to evaluate its behavior as an additive to improve the anticorrosion capacity on stainless steel samples. An electrochemical characterization by polarization curves and visual observation was carried out to evaluate the anticorrosive behavior of the modified paints. The results showed that the corrosion rate determined from the tafel plot was lower in the steel samples covered with paint and polyaniline. The concentration of $0.8 \%$ of polyaniline in the paint showed a corrosion rate 12 times lower than that of the polyaniline-free paint. Additionally, visual observations and measurements of failed area carried out by applying an accelerated corrosion process by immersion in a $3.5 \% \mathrm{NaCl}$ aqueous solution, allowed determining that, at a time of exposure of $300 \mathrm{~h}$, corrosion inhibition can be achieved 26 times greater with the addition of $0.8 \%$ polyaniline. These results allowed to conclude that the addition of polyaniline by means of a simple mixture, significantly improved the anticorrosive protection capacity of a commercial epoxy paint.
\end{abstract}

Keywords: commercial paint, corrosion, electrochemistry, polyaniline

\section{Introduction}

Intrinsic conducting polymers (ICP) are materials that combine many of the properties of traditional polymeric materials such as high strength/density ratio, excellent properties for thermal insulation and good resistance to acids, alkalis and solvents and properties of metals such as conductivity electrical, magnetic properties and thermal properties [1-3]. These characteristics have allowed them to be used in a large number of devices such as rechargeable batteries, LEDs, artificial muscles, electronic tongues, electronic noses, among others [4-9].

Polyaniline (PANI) is one of the most popular and widely used intrinsic conducting polymers due to its good stability, low cost, good adhesion capacity, and excellent electrochemical and optical properties [10-12]. One of the most studied applications is its use as anticorrosive protection for metals such as stainless steel, iron, aluminum, among others [13-15].

The great interest aroused by polyaniline as protection against corrosion, is possibly due to the fact that corrosion is a problem that affects a wide sector of industry and construction. Therefore, is the focus of a large number of investigations, focused on understanding the phenomenon and develop strategies to avoid or delay it. However, there is no method that guarantees total and permanent protection of metals, so the existing methods do not permanently solve the problem, but rather extend the life of the metal structures. In this sense, polyaniline has shown to be a promising alternative due to its high resistance to the diffusion of corrosive ions and also its conductivity allows it to act as separate from partial anodic and cathodic reactions.

*email: alvaro.arrieta@unisucre.edu.co 
There are several methods in which polyaniline can be synthesized, through photochemical, electrochemical, microwave, chemical oxidation methods, among others [16-18]. However, the most widely used methods in corrosion protection applications are the electropolymerization method and chemical synthesis. Although the use of electropolymerized polyaniline as a protective coating against corrosion of steel has been used successfully by several authors, this method is limited by the loss of adhesion and the low practicality to be applied on large surfaces. On the other hand, chemical synthesis offers the possibility of applying the protective layer of aniline by using different methods and can be used on large surfaces. Polyaniline can be applied individually or combined with other substances (epoxy, acrylic, polyurethanes, among others) or surface pre-treatments [19-21].

There are numerous works where the application of polyaniline as an anticorrosive treatment is reported, either by electropolymerization or by coating such as paint. However, few studies have been conducted evaluating the behavior of polyaniline as an additive to commercial anti-corrosion epoxy paints. This work presents a study of the performance of a commercial anticorrosive paint modified with polyaniline at various concentrations. The performance evaluation was carried out on stainless steel specimens exposed to an accelerated process of corrosion in $3.5 \% \mathrm{NaCl}$. The protection capacity was studied by electrochemical techniques and by visual observation.

\section{Materials and methods}

The reagents used were purchased from Sigma-Aldrich, aniline $\left(\mathrm{C}_{6} \mathrm{H}_{5} \mathrm{NH}_{2}\right)$, ammonium persulfate $\left(\left(\mathrm{NH}_{4}\right)_{2} \mathrm{~S}_{2} \mathrm{O}_{8}\right)$, oleic acid $\left(\mathrm{CH}_{3}\left(\mathrm{CH}_{2}\right)_{7} \mathrm{CH}=\mathrm{CH}\left(\mathrm{CH}_{2}\right)_{7} \mathrm{COOH}\right)$ and locally purchased epoxy anticorrosive paint prepared under the technical standards NTC OHSAS 18001, NTC 2450, ISO 9001 and ISO 14001.

The stainless steel samples consisted of cool roll steel specimens, which were cut with a cutting disc and a hole was made with a milling machine to hold them, the dimensions of these specimens are shown in Figure 1. To prepare the surface, it was applied the SSPC-SP1 method, in which oils, greases or other chemicals present on said surface were removed with a polishing disc. Subsequently, the SSPS-SP2 method was applied, passing abrasive paper on the surface.

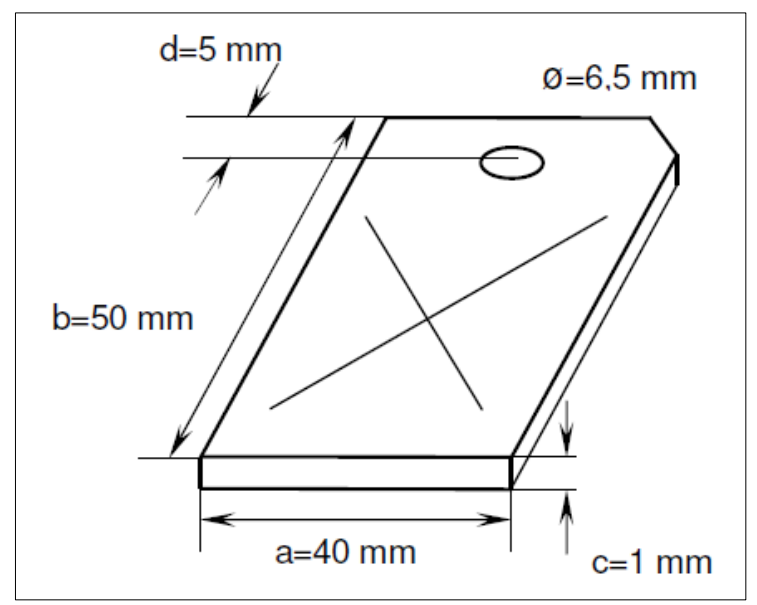

Figure 1. Dimensions of the stainless-steel specimen used in the corrosion tests

For the chemical synthesis of soluble polyaniline, $1 \mathrm{~mol}$ of aniline $(99.5 \%)$ and $1 \mathrm{~mol}$ of oleic acid $(99.8 \%)$ were added in $2.5 \mathrm{~L}$ of water with stirring in a chilled water bath for 90 min with constant stirring of 1200 r.p.m. $500 \mathrm{~mL}$ of aqueous solution, containing $1 \mathrm{~mol}$ of ammonium persulfate, were taken and added dropwise to the emulsion over a period of $60 \mathrm{~min}$ with constant stirring of 1500 r.p.m. The obtained mixture remained under stirring and was allowed to react for $4 \mathrm{~h}$. The obtained product was filtered and washed with water and ethanol 3 times and the obtained powder was dried at $40^{\circ} \mathrm{C}$ for $24 \mathrm{~h}$ under vacuum. 
Once the polyaniline was synthesized, the commercial epoxy paint was prepared by adding polyaniline at different concentrations. The concentrations tested were $0.3,0.5,0.8,1.0,1.2,1.5,1.7$, 2.0, 2.2, 2.5, 2.8, 3.0 and 3.5\%. Additionally, a control (paint without polyaniline) was used (0\%). All the specimens were prepared in triplicate.

Once the epoxy paint was modified, it was applied using a spray gun on the specimens previously prepared and treated according to the technical standards SSPC-SP1 and SSPS-SP2. A single coat of paint was applied to each of the specimens, and a second coat of paint was applied to the edges and holes, as these are areas of high level of attack by corrosion. To guarantee optimum adherence, the paints were left to dry for a period of 3 days. After this time, an " $\mathrm{X}$ " shaped cut was made to guarantee the attack by corrosion.

An electrochemical characterization was carried out by means of polarization curve measurements or tafel plot, to evaluate the corrosion potentials, corrosion currents and determine the corrosion rate. Measurements were carried out with a PAR EG\&G 2263 potentiostat/galvanostat controlled by PowerSuit software. The cell used was a cell with $3.5 \% \mathrm{NaCl}$ and a traditional three-electrode configuration, an $\mathrm{Ag} / \mathrm{AgCl}$ reference electrode, a $1 \mathrm{~cm} \times 2 \mathrm{~cm}$ platinum foil as the counter electrode and the stainless steel specimens as working electrodes. Additionally, the specimens were subjected to an accelerated corrosion process, which consisted of immersing the specimens in a $3.5 \% \mathrm{NaCl}$ aqueous solution to immersion times of 72, 140, 220 and $300 \mathrm{~h}$ and using open circuit potential (OCP). The anticorrosive treatment was evaluated at 72,140, 220 and $300 \mathrm{~h}$ by visual evaluation following the ASTM-D 1654 standard method.

\section{Results and discussions}

Once the specimens were completely dry, polarization measurements were carried out to determine oxidation potentials and oxidation currents. In Figure 2, the polarization curves obtained with the specimens treated with paints with $0.0,0.3,0.8,1.5,2.2$, and $3.0 \%$ polyaniline are presented, not all the polarization curves were included for better visualization. It was observed that the corrosion potentials in the curves were around $0.7 \mathrm{~V}$, with small variations of less than $0.05 \mathrm{~V}$ being observed among them.

On the other hand, the variations in the corrosion currents were more marked and these determined values for each one of the test specimens allow to determine the corrosion rate (CR) by applying the following equation:

$$
C R=\frac{\text { Icorr } \cdot k \cdot E W}{d}
$$

where $\mathrm{k}$ is the constant that defines the units for the corrosion rate $(\mathrm{mm} / \mathrm{A} \mathrm{cm}$ year), EW the equivalent weight in grams/equivalent and $\mathrm{d}$ is the density in $\mathrm{g} \mathrm{cm}^{-3}$. Table 1 shows the values of corrosion potentials and corrosion currents calculated from the polarization curves and corrosion rates determined from equation 1 , for each of the test specimens studied.

In Table 1 it can be seen that the corrosion potentials range from the most positive potential at -683.47 $\mathrm{mV}$ to the most negative potential $-738.52 \mathrm{mV}$. It can be observed that the electropositive values of corrosion potential were obtained at low concentrations of polyaniline (from $0.3 \%$ to $1.2 \%$ ), this may be indicative of a more noble character in these treatments. Regarding the corrosion current, it could be observed that it is significantly higher at concentrations greater than $2.0 \%$, and in the specimen treated epoxy paint without polyaniline. Furthermore, low corrosion current values were obtained with the specimens covered with paint and low concentrations of polyaniline.

Additionally, the corrosion rate is much lower in the test specimens with polyaniline concentrations ranging from $0.3 \%$ to $0.8 \%$ and increases at concentrations greater than $2.0 \%$. The previous results indicate that low concentrations of polyaniline have a better protection capacity than that observed with epoxy paints with a higher concentration of polyaniline. The coating with the content of polyaniline at $0.8 \%$ presented a corrosion rate 12 times lower than the coatings without polyaniline. In general terms, 
all the specimens treated with polyaniline coatings showed lower corrosion rates than that calculated for the specimen coated with the epoxy paint without polyaniline. In addition, paints with a lower amount of polyaniline show better corrosion protection than paints with a higher amount of polyaniline. This shows that the addition of polyaniline to the epoxy paint improves the protection against corrosion.

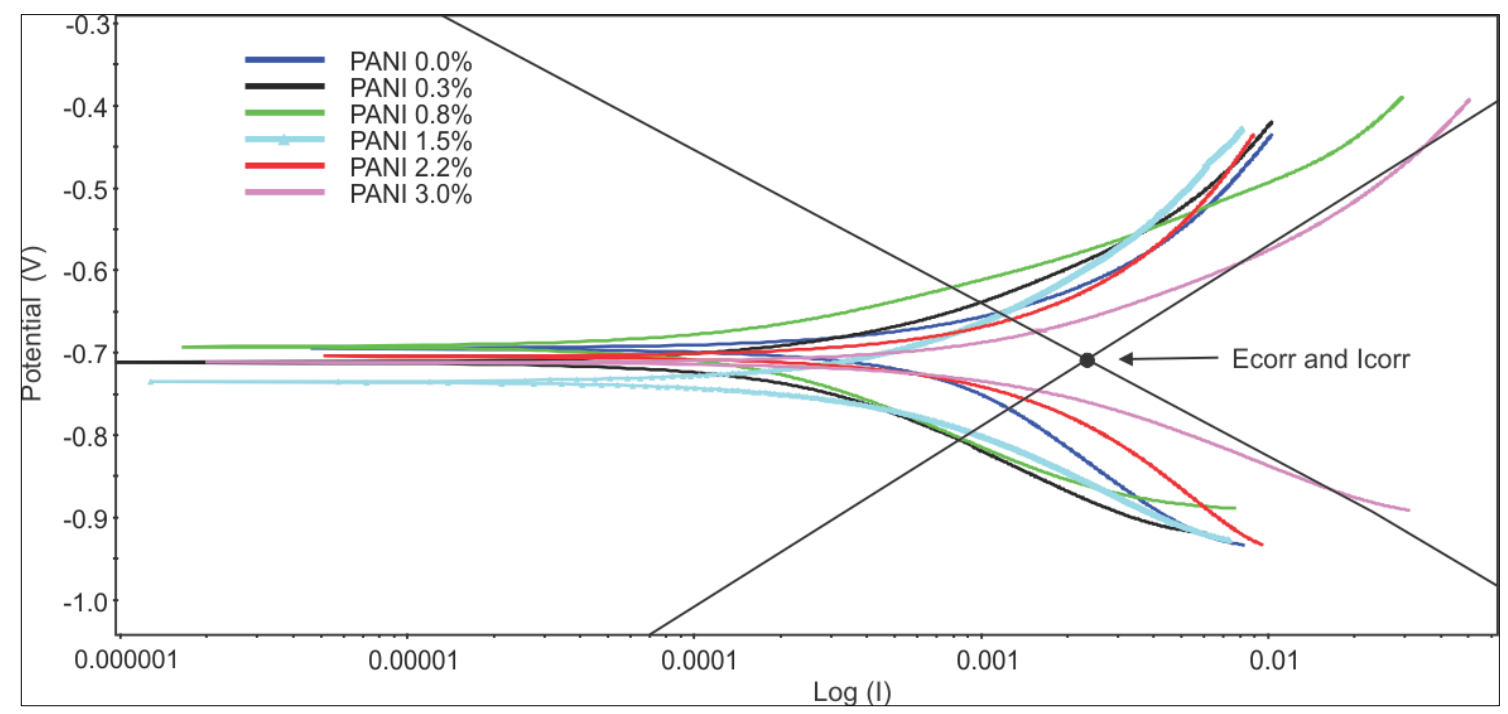

Figure 2. Polarization curves of test specimens covered with epoxy paint/polyaniline systems at different concentrations

Undoubtedly, electrochemical measurements allow an effective evaluation of corrosion processes, visual observations are also a reliable measurement tool for this process. Therefore, the effect of the addition of polyaniline was evaluated through visual observations of the specimens subjected to an accelerated corrosion process. For this, the samples were immersed in a 3.5\% $\mathrm{NaCl}$ aqueous solution and different immersion times were evaluated, which were 72, 140, 220 and $300 \mathrm{~h}$.

Table 1. Values of corrosion currents, corrosion potentials and corrosion rates obtained from the polarization curves

\begin{tabular}{|c|c|c|c|}
\hline Test specimen & $\begin{array}{c}\text { corrosion current } \\
{\left[\boldsymbol{\mu A} / \mathbf{c m}^{\wedge} \mathbf{2}\right]}\end{array}$ & $\begin{array}{c}\text { Corrosion } \\
\text { potential }[\mathbf{m V}]\end{array}$ & $\begin{array}{c}\text { Corrosion rate } \\
{[\mathbf{m m} / \mathbf{y e a r}]}\end{array}$ \\
\hline PANI 0.0\% & 273.90 & -704.91 & 128.2193 \\
\hline PANI 0.3\% & 46.16 & -693.78 & 21.0015 \\
\hline PANI 0.5\% & 47.01 & -685.86 & 21.3882 \\
\hline PANI 0.8\% & 23.96 & -692.84 & 10.9011 \\
\hline PANI 1.0\% & 101.70 & -695.31 & 46.2707 \\
\hline PANI 1.2\% & 109.00 & -683.47 & 49.5920 \\
\hline PANI 1.5\% & 72.87 & -735.40 & 33.1539 \\
\hline PANI 1.7\% & 80.51 & -711.10 & 35.8812 \\
\hline PANI 2.0\% & 83.02 & -738.52 & 37.7577 \\
\hline PANI 2.2\% & 246.90 & -704.59 & 125.9821 \\
\hline PANI 2.5\% & 251.30 & -706.75 & 122.2582 \\
\hline PANI 2.8\% & 171.00 & -736.57 & 77.8004 \\
\hline PANI 3.0\% & 186.01 & -711.93 & 84.6250 \\
\hline PANI 3.5\% & 139.60 & -738.17 & 63.5142 \\
\hline
\end{tabular}


Immediately after removing each test specimen from the corrosive environment ( $\mathrm{NaCl}$ solution), it was washed with distilled water by immersion in a period of 15 seconds and the detached material was removed with a spatula. The spatula was positioned vertically in relation to the face of the test piece and parallel to the cut ("X"). For this procedure, the ASTM-D 1654 standard method was followed. Subsequently, the distance from the cut " $X$ " to the greatest distance where there was material detachment was measured with graph paper, in order to determine the percentage of failed area of each test specimen analyzed. Figure 3 shows the images of the specimens covered with paint without polyaniline (PANI 0\%) and paint with $0.3 \%$ polyaniline in times of exposure to accelerated corrosion.

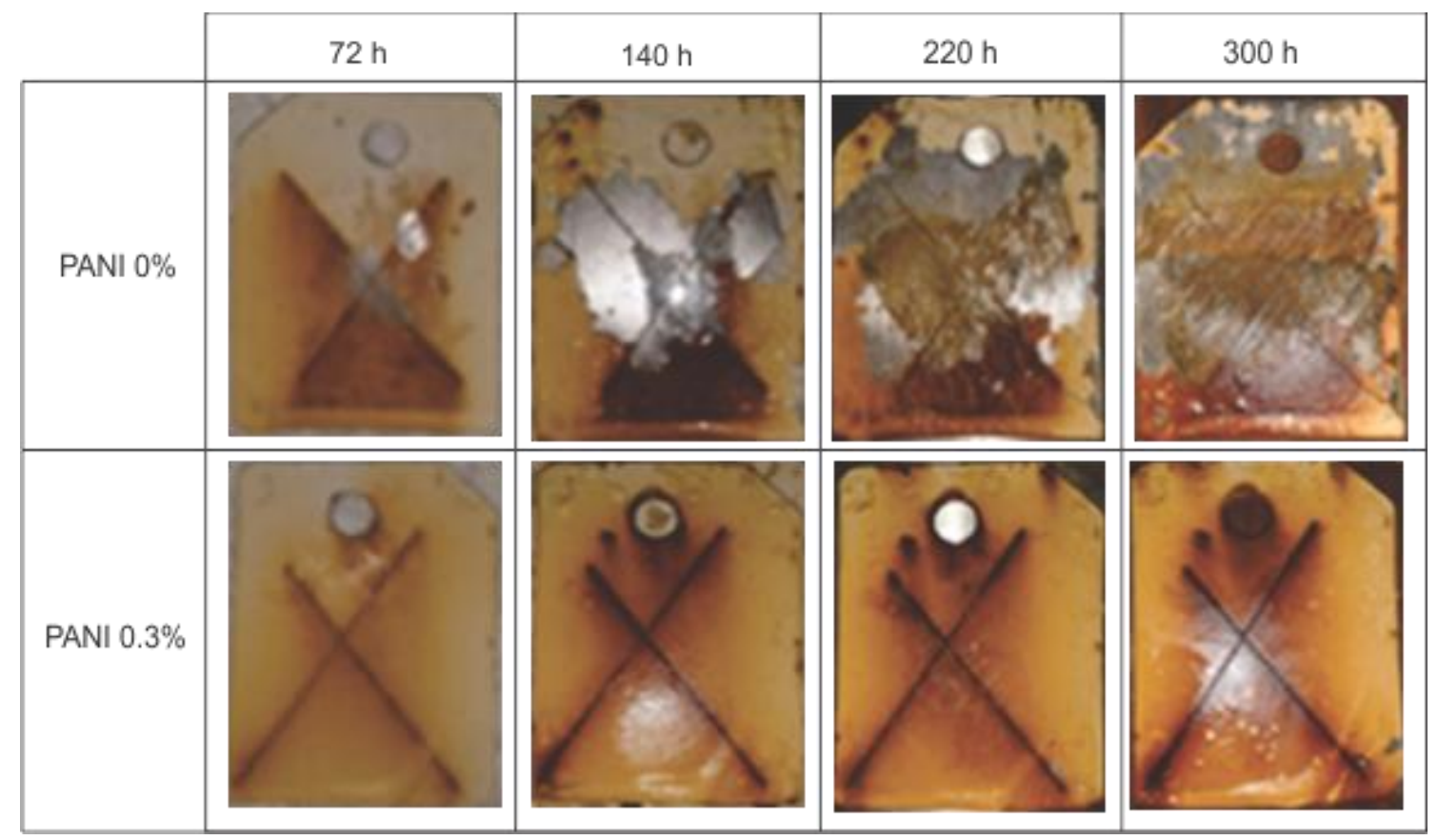

Figure 3. Photographic image $(5 x)$ of the failed area in the specimens covered with epoxy paint without polyaniline (PANI 0\%) and epoxy paint with $0.3 \%$ polyaniline (PANI $0.3 \%$ ) at different times of exposure in saline solution

In Figure 3 it can be clearly seen that the specimen covered with epoxy paint without polyaniline has a greater failed area, while the specimen covered with epoxy paint with polyaniline (PANI 0.3\%), shows very little failed area and also maintains the coating in practically the entire test specimen. After $72 \mathrm{~h}$ of exposure, the specimens covered with epoxy paint without polyaniline already show a small failed area, after $140 \mathrm{~h}$ the area of corrosion is significantly greater than that observed in the specimen covered with epoxy paint with polyaniline and at $300 \mathrm{~h}$ the sample covered with epoxy paint without polyaniline showed a large failed area.

In order to carry out a rigorous visual evaluation, the ASTM-D 1654 standard was applied and the percentage of failed area was determined. The measurements of the percentage of failed area made in each of the specimens are recorded in Figure 4. It can be seen that epoxy paint with polyaniline in concentrations of $0.3,0.5$ and $0.8 \%$, have a better anticorrosive behavior during the $300 \mathrm{~h}$ of exposure of the specimens. In this way, $3 \%$ of the failed area with epoxy paint with $0.8 \%$ of polyaniline was reached and 8.5 and $13.0 \%$ of the failed area was reached in specimens covered with epoxy paint with 0.5 and $0.3 \%$ of polyaniline, respectively.

The epoxy paint without polyaniline content (PANI 0\%) reached a corrosion area of 80\%, which means that more than a third of the specimen showed corrosion after $300 \mathrm{~h}$ of exposure in the saline solution. This result indicates that the coating with epoxy paint and $0.8 \%$ polyaniline presented a degree of protection 26.6 times higher than the epoxy paint without polyaniline. The other two best results, 
PANI 0.5 and PANI $0.3 \%$, had a degree of protection of 9.4 and 6.1 times higher than epoxy paint without polyaniline.

These results show concordance with those obtained with electrochemical studies where it was evident that polyaniline concentrations in epoxy paint less than $2 \%$, presented better anticorrosive protection than higher concentrations. In addition, all the treatments with polyaniline presented better anticorrosive protection than the epoxy paint without polyaniline (PANI 0\%). This indicates that the addition of polyaniline independent of its concentration, can improve the anticorrosive properties of epoxy paints.

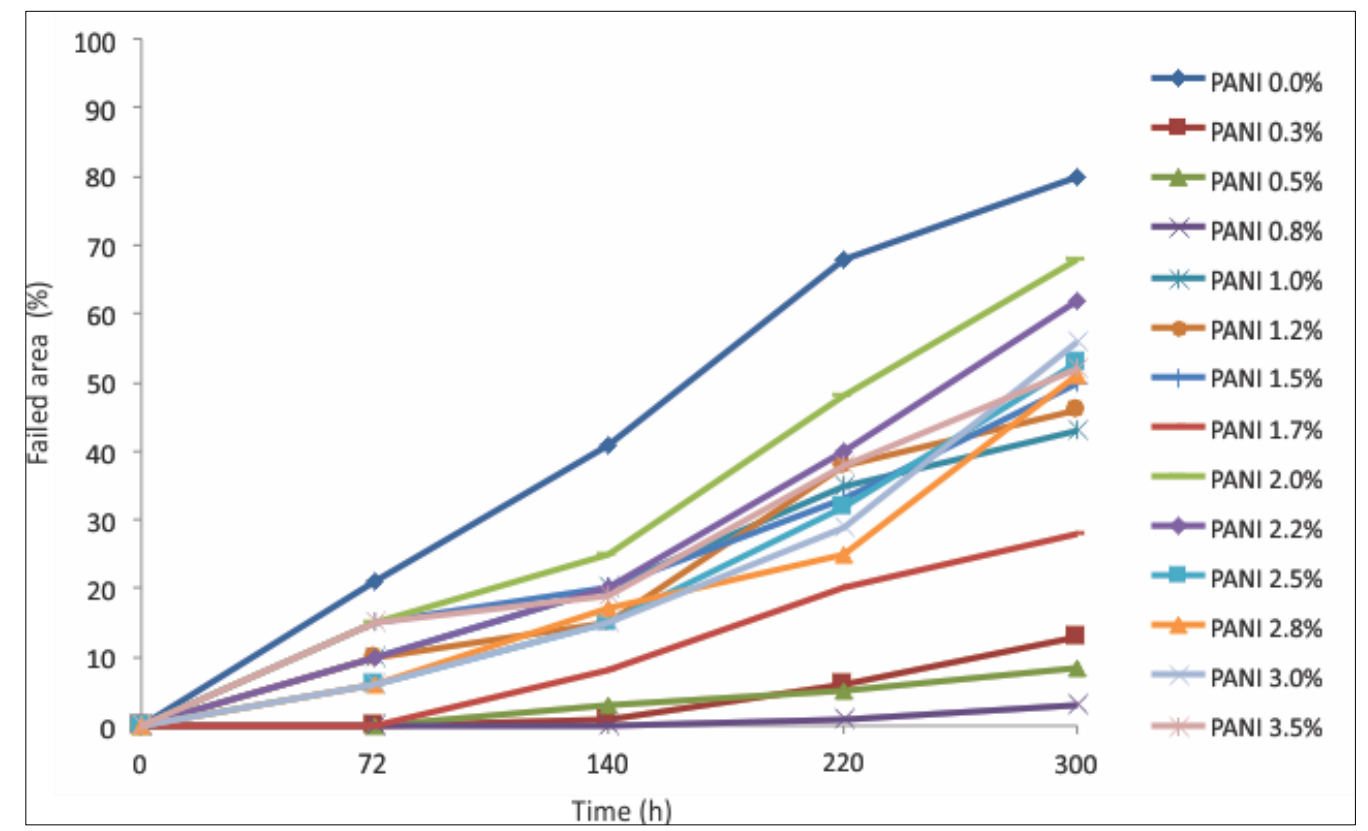

Figure 4. Percentage of failed area as a function of the exposure time in saline solution the specimens covered with epoxy paint without polyaniline and with polyaniline at various concentrations

\section{Conclusions}

The results presented and previously described allow to conclude that the exposure to an environment of accelerated corrosion of specimens covered with epoxy paint with polyaniline show greater resistance to corrosion than the epoxy paint without polyaniline used as a control. Electrochemical studies allowed estimating that polyaniline added by $0.8 \%$ in epoxy paint improves its anticorrosive efficiency 12 times, while visual observations allowed establishing a protection capacity of 26.6 times greater for this same polyaniline concentration in the epoxy paint.

Regardless of the polyaniline concentration used to modify the epoxy paint, it improves its anticorrosive properties. However, amounts of polyaniline less than $2 \%$, have greater protection capacity than higher concentrations.

Acknowledgments: The authors Acknowledgment the University of Sucre for financial support.

\section{References}

1.WANG, Y., ZHU, C., PFATTNER, R., YAN, H., JIN, L., CHEN, S., et. al. A highly stretchable, transparent, and conductive polymer. Science Advances. 3(3), 2017, 1-10.

https://doi.org/10.1126/sciadv.1602076.

2.LE, T.H., KIM, Y., YOON, H. Electrical and Electrochemical Properties of Conducting Polymers. Polymers. 9(12), 2017, 1-32. https://doi.org/10.3390/polym9040150. 
3.SHIRAKAWA, H. The Discovery of Polyacetylene Film: The Dawning of an Era of Conducting Polymers (Nobel Lecture). Angewandte Chemie International Edition. 40(14), 2001, 2574-2580. https://doi.org/10.1002/1521-3773(20010716)40:14<2574::AID-ANIE2574>3.0.CO;2-N.

4ZHONG, Y. Electronic nose for food sensory evaluation. Jian Zhong and Xichang Wang, editors. Evaluation Technologies for Food Quality. Elsevier. 2019, 7-22.

https://www.elsevier.com/books/evaluation-technologies-for-food-quality/zhong/978-0-12-814217-2. 5.ARRIETA, A.A., RODRÍGUEZ-MÉNDEZ, M.L., DE SAJA, J.A., BLANCO, C.A., NIMUBONA, D. Prediction of bitterness and alcoholic strength in beer using an electronic tongue. Food Chemistry. 123(3), 2010, 642-646. https://doi.org/10.1016/j.foodchem.2010.05.006.

6.JEONG, S.H., KIM, H., PARK, M.H., LEE, Y., LI, N., SEO, H.K., et. al. Ideal conducting polymer anode for perovskite light-emitting diodes by molecular interaction decoupling. Nano Energy. 60, 2019, 324-331. https://doi.org/10.1016/j.nanoen.2019.03.030.

7.NÚÑEZ, Y.E., ARRIETA, A.A., SEGURA, J.A., BERTEL, S.D. Synthesis of an air-working trilayer artificial muscle using a conductive cassava starch biofilm (manihot esculenta, cranz) and polypyrrole (PPy). Journal of Physics: Conference Series. 687, 2016, 1-7.

https://doi.org/10.1088/1742-6596/687/1/012042.

8.LIU, B., BO, R., TAHERI, M., DI BERNARDO, I., MOTTA, N., CHEN, H., et. al. Metal-Organic Frameworks/Conducting Polymer Hydrogel Integrated 3D Free-Standing Monoliths as Ultrahigh Loading Li-S Battery Electrodes. Nano Letters. 19, 2019, 4391-4399.

https://doi.org/10.1021/acs.nanolett.9b01033.

9.PALZA, H., ZAPATA, P., ANGULO-PINEDA, C. Electroactive Smart Polymers for Biomedical Applications. Materials. 12(2), 2019, 1-24. https://doi.org/10.3390/ma12020277.

10.LI, G.R., FENG, Z.P., ZHONG, J.H., WANG, Z.L., TONG, Y.X. Electrochemical Synthesis of Polyaniline Nanobelts with Predominant Electrochemical Performances. Macromolecules. 43(5), 2010, 2178-2183. https://doi.org/10.1021/ma902317k.

11.WATANABE, A., MORI, K., IWASAKI, Y., NAKAMURA, Y., NIIZUMA, S. Electrochromism of polyaniline film prepared by electrochemical polymerization. Macromolecules. 20(8), 1987, 1793-1796. https://doi.org/10.1021/ma00174a015.

12.GUPTA, V., MIURA, N. High performance electrochemical supercapacitor from electrochemically synthesized nanostructured polyaniline. Materials Letters. 60(12), 2006, 1466-1469.

https://doi.org/10.1016/j.matlet.2005.11.047.

13.KRALJIC, M., MANDIC, Z., DUIC, L. Inhibition of steel corrosion by polyaniline coatings. Corrosion Science. 45(1), 2003, 181-198. https://doi.org/10.1016/S0010-938X(02)00083-5.

14.JEYAPRABHA, C., SATHIYANARAYANAN, S., VENKATACHARI, G. Polyaniline as corrosion inhibitor for iron in acid solutions. Journal of Applied Polymer Science. 101(4), 2006, 2144-2153.

https://doi.org/10.1002/app.22579.

15.ZHANG, X. Electrochemical Evidence of Corrosion Resistance of Polyaniline Film on the Copper Surface. International Journal of electrochemical science. 15, 2020, 4470-4480.

https://doi.org/10.20964/2020.05.46.

16.SALAH ABDULLA, H., SALLY ADEL, A.H. Chemical Synthesis and Characterization of Conducting Polyaniline. Baghdad Science Journal. 17(1), 2020, 106-111.

https://doi.org/10.21123/bsj.2020.17.1.0106

17.HIEN TRAN, T., DEBARNOT, D., RICHAUD. E. Thermal oxidative stability of polyanilines. Polymer Testing. 81, 2020, 1-7. http://dx.doi.org/10.1016/j.polymertesting.2019.106187.

18.KUMARI JANGID, N., JADOUN, S., KAUR, N. A Review on high-throughput Synthesis, Deposition of Thin Films and properties of Polyaniline. European Polymer Journal. 125, 2020, 1-6.

http://dx.doi.org/doi:10.1016/j.eurpolymj.2020.109485.

19.LIU, S., LIU, L., LI, Y., WANG, F. Effects of N-alkylation on anticorrosion performance of doped polyaniline/epoxy coating. Journal of Materials Science \& Technology. 39, 2020, 48-55.

https://doi.org/10.1016/j.jmst.2019.06.012. 
20.DINIZ, F.B., DE ANDRADE, G.F., MARTINS, C.R., DE AZEVEDO, W.M. A comparative study of epoxy and polyurethane based coatings containing polyaniline-DBSA pigments for corrosion protection on mild steel. Progress in Organic Coatings. 76(5), 2013, 912-916.

https://doi.org/10.1016/j.porgcoat.2013.02.010.

21.JAFARZADEH, S., CLAESSON, P.M., SUNDELL, P.E., TYRODE, E., PAN, J. Active corrosion protection by conductive composites of polyaniline in a UV-cured polyester acrylate coating. Progress in Organic Coatings. 90, 2016, 154-162. https://doi.org/10.1016/j.porgcoat.2015.10.008.

Manuscript received: 9.03 .2021 